\title{
Removal of benzylidene acetal and benzyl ether in carbohydrate derivatives using triethylsilane and $\mathrm{Pd} / \mathrm{C}$
}

\author{
Abhishek Santra, Tamashree Ghosh and Anup Kumar Misra*
}

\author{
Full Research Paper \\ Address: \\ Bose Institute, Division of Molecular Medicine, P-1/12, C.I.T. Scheme \\ VII-M, Kolkata-700054, India; FAX: 91-33-2355 3886 \\ Email: \\ Anup Kumar Misra* - akmisra69@gmail.com \\ * Corresponding author \\ Keywords: \\ benzylidene; glycoside; Pd/C; transfer hydrogenation; triethylsilane
}

\author{
Beilstein J. Org. Chem. 2013, 9, 74-78. \\ doi:10.3762/bjoc.9.9 \\ Received: 12 October 2012 \\ Accepted: 17 December 2012 \\ Published: 14 January 2013 \\ Associate Editor: M. Rueping \\ (C) 2013 Santra et al; licensee Beilstein-Institut. \\ License and terms: see end of document.
}

\begin{abstract}
Clean deprotection of carbohydrate derivatives containing benzylidene acetals and benzyl ethers was achieved under catalytic transfer hydrogenation conditions by using a combination of triethylsilane and $10 \% \mathrm{Pd} / \mathrm{C}$ in $\mathrm{CH}_{3} \mathrm{OH}$ at room temperature. A variety of carbohydrate diol derivatives were prepared from their benzylidene derivatives in excellent yield.
\end{abstract}

\section{Introduction}

Functionalization of carbohydrate intermediates is essential for their assembly towards the synthesis of complex oligosaccharides [1-9]. Benzylidene acetal is a frequently used protecting group for the simultaneous protection of 1,2- and 1,3-diol derivatives [10,11]. It can be removed under acidic hydrolysis as well as under neutral conditions (e.g., hydrogenolysis). The benzylidene acetal can also be regioselectively opened under reductive conditions to produce partially benzylated derivatives [12-14]. A number of methods have been reported for the removal of benzylidene acetals by using strong protic and Lewis acids $[10,11,15]$ as well as some heterogeneous acidic catalysts $[16,17]$. Removal of benzylidene acetal under nonacidic conditions includes hydrogenolysis using hydrogen gas over Pd/C [18], or treatment with hydrazine [19] or $\mathrm{EtSH}$ [20] or $\mathrm{Na} / \mathrm{NH}_{3}$ [21], etc. However, most of the abovementioned methodologies have several shortcomings, such as harsh conditions, formation of unwanted byproducts, longer reaction time, incompatibility of functional groups, use of expensive reagents, fire hazard, etc. In this context, the development of a mild, neutral reaction condition for the removal of benzylidene acetals would be useful in the derivatization of a carbohydrate framework. Mandal et al. reported the removal of benzyl esters/ethers and the reduction of alkenes/alkynes by catalytic transfer hydrogenation using a combination [22] of triethylsilane $\left(\mathrm{Et}_{3} \mathrm{SiH}\right)$ and $10 \% \mathrm{Pd} / \mathrm{C}$. In our synthetic endeavor we sought to explore the catalytic potential of a combination of $\mathrm{Et}_{3} \mathrm{SiH}$ and $10 \% \mathrm{Pd} / \mathrm{C}$ in the deprotection of a benzylidene group in the carbohydrate derivatives, without the formation of 


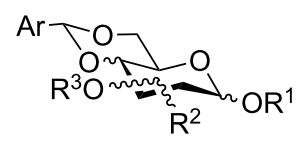

$\mathrm{R}^{1}$ : alkyl, aryl, glucopyranosyl

$\mathrm{R}^{2}$ : OAc, OBn, OBz, azide, $N$-phthaloyl

$\mathrm{R}^{3}$ : Ac, Bn, Bz, rhamnopyranosyl

Ar: Ph, PMP

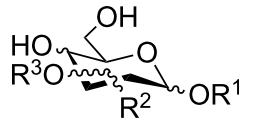

$\mathrm{R}^{1}$ : alkyl, aryl, glucopyranosyl

$\mathrm{R}^{2}$ : $\mathrm{OH}, \mathrm{OAc}, \mathrm{NH}_{2}, \mathrm{~N}$-phthaloyl

$\mathrm{R}^{3}$ : Ac, $\mathrm{H}$, rhamnopyranosyl

Scheme 1: Removal of benzylidene acetal and benzyl ether by using a combination of triethylsilane and $10 \% \mathrm{Pd} / \mathrm{C}$.

unwanted byproducts. We report herein our findings on the removal of benzylidene acetal using a combination of triethylsilane and $10 \% \mathrm{Pd} / \mathrm{C}$ (Scheme 1).

\section{Results and Discussion}

In a set of initial experiments, methyl 2,3-di- $O$-acetyl-4,6- $O$ benzylidene- $\alpha$-D-glucopyranoside (1) was treated with a combination of a varied quantity of triethylsilane (1.0-5.0 equiv of the substrate) and $10 \% \mathrm{Pd} / \mathrm{C}(10-20 \mathrm{mg}$ per $100 \mathrm{mg}$ substrate) in $\mathrm{CH}_{3} \mathrm{OH}$ at room temperature. It was observed that the use of a total 3.0 equiv of triethylsilane and $10 \% \mathrm{Pd} / \mathrm{C}(10 \mathrm{mg} / 100 \mathrm{mg}$ of substrate) in $\mathrm{CH}_{3} \mathrm{OH}$ at room temperature furnished the clean removal of the benzylidene group in a $87 \%$ yield in $30 \mathrm{~min}$. Generalizing the reaction conditions, a series of benzylidene acetal containing monosaccharide and disaccharide derivatives, with different functional groups present in them, were treated with the optimized reagent system, and clean removal of benzylidene acetal was observed in all cases. The effect of triethylsilane and $10 \% \mathrm{Pd} / \mathrm{C}$ on the removal of benzylidene acetal is presented in Table 1 . The noteworthy features of the reaction condition are: (a) neutral conditions; (b) compatibility with a large number of functional groups used in the protection of carbohydrates (e.g., acetyl, benzoyl, phthaloyl, 2-(trimethylsilyl)ethyl, 4-methoxyphenyl, etc.); (c) clean and high yielding; (d) no unwanted byproduct formation; (e) can be carried out at room temperature; (f) no flammable gas is required. The reaction conditions were equally effective for the removal of 4-methoxybenzylidene acetal (Table 1, entries 13-15). Allyl ether was reduced and benzyl ethers were removed under the reaction conditions, as expected from the earlier report [22] (Table 1, entry 8 and entries 3, 4, 9, 10, 12). Benzyl ethers and benzylidene acetal in a compound can be removed in one pot by using these reaction conditions (Table 1, entries $3,4,9,10,12)$. All debenzylidenated products were

\begin{tabular}{|c|c|c|c|c|c|}
\hline Entry & Substrate & Product $^{a}$ & Time $(\min )$ & Yield ${ }^{b}(\%)$ & Ref. $^{c}$ \\
\hline 1 & & & 30 & 87 & [23] \\
\hline 2 & $\begin{array}{r}\text { OAc } \\
3\end{array}$ & $\begin{array}{r}\mathrm{OAc} \\
4\end{array}$ & 30 & 85 & [24] \\
\hline 3 & 5 & $\begin{array}{l}\mathrm{OH} \\
6\end{array}$ & 60 & $90^{d}$ & [25] \\
\hline 4 & 7 & 8 & 60 & $88^{d}$ & - \\
\hline
\end{tabular}


Table 1: Conversions of carbohydrate derivatives effected with $\mathrm{Et}_{3} \mathrm{SiH}$ and $10 \% \mathrm{Pd} / \mathrm{C}$. (continued)

5

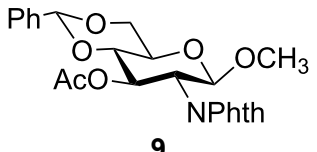

6
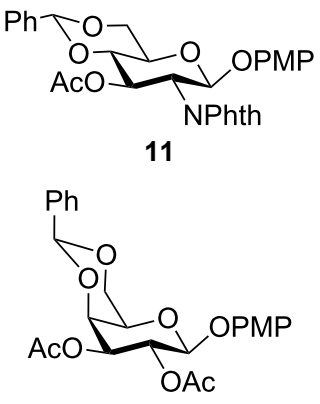

13

8

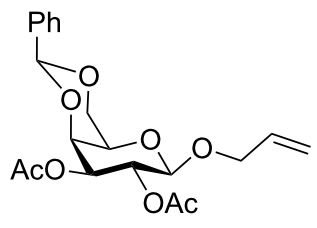

15

9

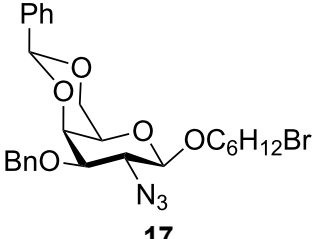

10

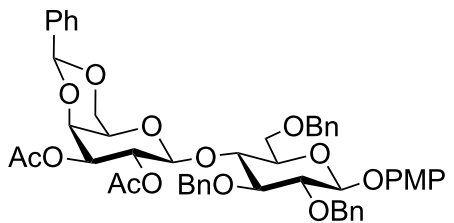

19

11

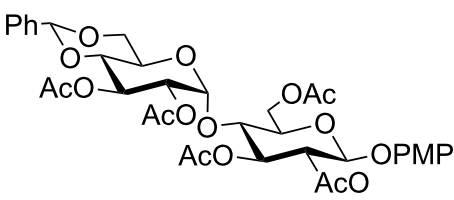

21

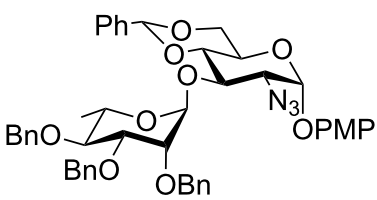

23

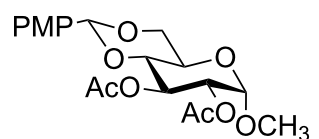

25

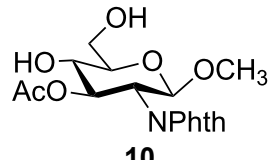

40

87

[26]

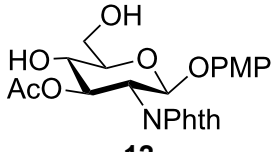

40

12

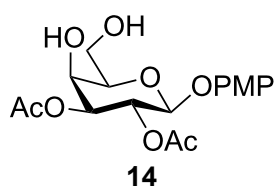

40

90

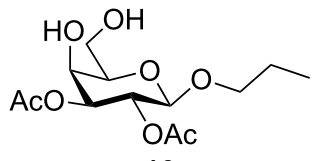

40

92

16

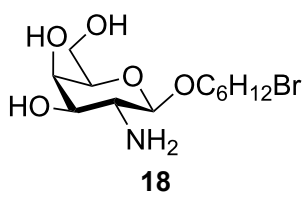

40

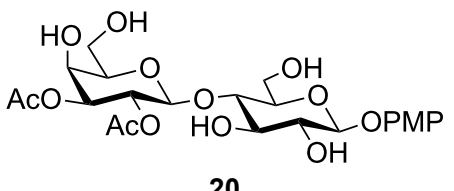

120

$77^{d}$

[28]

20

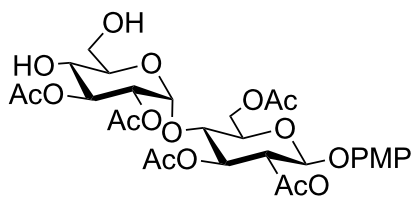

60

84

22

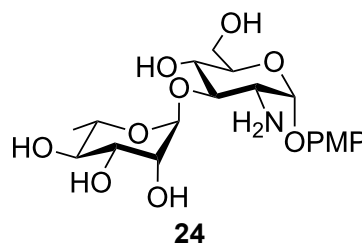

90

$80^{\mathrm{d}, \mathrm{e}}$

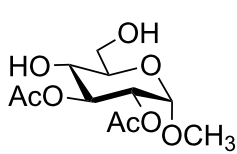

2 
Table 1: Conversions of carbohydrate derivatives effected with $\mathrm{Et}_{3} \mathrm{SiH}$ and $10 \% \mathrm{Pd} / \mathrm{C}$. (continued)

14

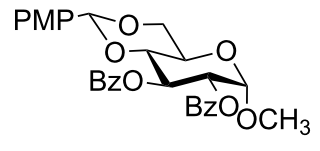

26

15

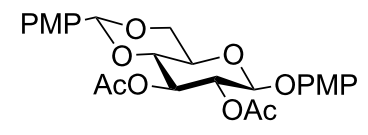

28

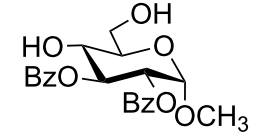

27

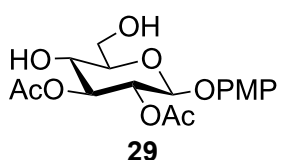

40

90

30

86

[29]

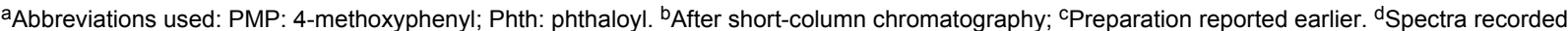
after per-O-acetylation using acetic anhydride and pyridine $(1: 1 ; \mathrm{v} / \mathrm{v}) .{ }^{\mathrm{e}} \mathrm{Azide}$ group reduced to amine.

characterized by NMR spectral analysis. Known compounds gave acceptable NMR spectra that matched the previously reported data.

\section{Conclusion}

In summary, the efficient deprotection of carbohydrate derivatives containing benzylidene acetal and $O$-benzyl groups under catalytic transfer hydrogenation conditions has been developed by using a combination of triethylsilane and $10 \% \mathrm{Pd} / \mathrm{C}$. The efficacy of this methodology is comparable to the conventional hydrogenation involving hydrogen gas and $\mathrm{Pd} / \mathrm{C}$, whereas it does not require handling of a flammable gas. Being operationally simple and high yielding, these reaction conditions will certainly be accepted as a useful alternative to those currently existing in this area.

\section{Experimental}

\section{Typical experimental procedure}

To a solution of compound 1 (500 mg, $1.36 \mathrm{mmol})$ and $10 \%$ $\mathrm{Pd}(\mathrm{OH})_{2} / \mathrm{C}(50 \mathrm{mg})$ in $\mathrm{CH}_{3} \mathrm{OH}(5 \mathrm{~mL})$ was added $\mathrm{Et}_{3} \mathrm{SiH}$ $(650 \mu \mathrm{L}, 4.07 \mathrm{mmol})$ portionwise, and the reaction mixture was stirred at room temperature for an appropriate time, given in Table 1. The reaction mixture was filtered through a Celite bed, and the filtering bed was washed with $\mathrm{CH}_{3} \mathrm{OH}$. The combined filtrate was concentrated under reduced pressure to give the crude product, which was passed through a short pad of $\mathrm{SiO}_{2}$ with EtOAc as eluant to give pure compound 2 (330 mg, $87 \%)$.

\section{Supporting Information}

\section{Supporting Information File 1}

Analytical data of new compounds, ${ }^{1} \mathrm{H}$ NMR and ${ }^{13} \mathrm{C}$ NMR spectra.

[http://www.beilstein-journals.org/bjoc/content/

supplementary/1860-5397-9-9-S1.pdf]

\section{Acknowledgements}

A. S. and T. G. thank CSIR, New Delhi for providing Senior and Junior Research Fellowships respectively. This work was supported by CSIR, New Delhi [Project No. 02 (0038)/11/ EMR-II].

\section{References}

1. Demchenko, A. V., Ed. Handbook of Chemical Glycosylation; Wiley-VCH: Weinheim, Germany, 2008. doi:10.1002/9783527621644

2. Ernst, B.; Hart, G. W.; Sinay, P., Eds. Carbohydrates in Chemistry and Biology; Wiley-VCH: Weinheim, Germany, 2000; Vol. 1.

3. Levy, D. E.; Fugedi, P., Eds. The Organic Chemistry of Sugars; CRC Press: Boca Raton, U.S.A., 2006.

4. Osborn, H. M. I., Ed. Carbohydrates: Best Synthetic Methods; Academic Press: New York, 2003.

5. Kovac, P., Ed. Carbohydrate Chemistry: Proven Synthetic Methods; CRC Press: Boca Raton, U.S.A., 2011; Vol. 1.

6. Hanessian, S., Ed. Preparative Carbohydrate Chemistry; CRC Press: Boca Raton, U.S.A., 1997.

7. Guo, J.; Ye, X.-S. Molecules 2010, 15, 7235-7265. doi:10.3390/molecules15107235

8. Codée, J. D. C.; Ali, A.; Overkleeft, H. S.; van der Marel, G. A. C. R. Chim. 2011, 14, 178-193. doi:10.1016/j.crci.2010.05.010

9. Boltje, T. J.; Li, C.; Boons, G.-J. Org. Lett. 2010, 12, 4636-4639. doi:10.1021/ol101951u

10. Greene, T. W.; Wuts, P. G. M. Protective Groups in Organic Synthesis, 3rd ed.; John Wiley and Sons: New York, 1999; pp 219-229. doi:10.1002/0471220574

11. Kocienski, P. J. Protecting Groups, 1st ed.; Georg Thieme Verlag: Stuttgart, Germany, 1994; pp 137-155.

12. Garegg, P. J. Regioselective Cleavage of O-Benzylidene Acetals to Benzyl Ethers. In Preparative Carbohydrate Chemistry; Hanessian, S., Ed.; Marcel Dekker: New York, 1997; pp 53-67.

13. Garegg, P. J. Pure Appl. Chem. 1984, 56, 845-858. doi:10.1351/pac198456070845

14. Ohlin, M.; Johnsson, R.; Ellervik, U. Carbohydr. Res. 2011, 346, 1358-1370. doi:10.1016/j.carres.2011.03.032

15. Jarowicki, K.; Kocienski, P. J. J. Chem. Soc., Perkin Trans. 1 2001, 2109-2135. doi:10.1039/B103282H

16. Agnihotri, G.; Misra, A. K. Tetrahedron Lett. 2006, 47, 3653-3658. doi:10.1016/j.tetlet.2006.03.133 
17. Kumar, P. S.; Kumar, G. D. K.; Baskaran, S. Eur. J. Org. Chem. 2008, 6063-6067. doi:10.1002/ejoc.200800963

18. Hartung, W. H.; Simonoff, R. Org. React. 1953, 7, 263-326.

19. Bieg, T.; Szeja, W. Synthesis 1986, 317-318. doi:10.1055/s-1986-31597

20. Nicolaou, K. C.; Veale, C. A.; Hwang, C.-K.; Hutchinson, J.; Prasad, C. V. C.; Ogilvie, W. W. Angew. Chem., Int. Ed. Engl. 1991, 30, 299-303. doi:10.1002/anie.199102991

21. Nayak, U. G.; Brown, R. K. Can. J. Chem. 1966, 44, 591-602. doi:10.1139/v66-080

22. Mandal, P. K.; McMurray, J. S. J. Org. Chem. 2007, 72, 6599-6601. doi:10.1021/jo0706123

23. Adinolfi, M.; De Napoli, L.; Di Fabio, G.; Iadonisi, A.; Montesarchio, D.; Piccialli, G. Tetrahedron 2002, 58, 6697-6704. doi:10.1016/S0040-4020(02)00684-1

24. Hasegawa, A.; Ogawa, M.; Ishida, H.; Kiso, M. J. Carbohydr. Chem. 1990, 9, 393-414. doi:10.1080/07328309008543841

25. Akita, H.; Kawahara, E.; Kato, K. Tetrahedron: Asymmetry 2004, 15, 1623-1629. doi:10.1016/j.tetasy.2004.03.046

26. Kochetkov, N. K.; Byramova, N. E.; Tsvetkov, Yu. E.; Backinowsky, L. V. Tetrahedron 1985, 41, 3363-3375. doi:10.1016/S0040-4020(01)96688-8

27. Wang, P.; Wang, J.; Guo, T. T.; Li, Y. Carbohydr. Res. 2010, 345, 607-620. doi:10.1016/j.carres.2010.01.002

28. Zhang, Z.; Magnusson, G. Carbohydr. Res. 1996, 295, 41-55. doi:10.1016/S0008-6215(96)90118-4

29. Gu, G.; Fang, M.; Liu, J.; Gu, L. Carbohydr. Res. 2011, 346, 2406-2413. doi:10.1016/j.carres.2011.08.026

\section{License and Terms}

This is an Open Access article under the terms of the Creative Commons Attribution License (http://creativecommons.org/licenses/by/2.0), which permits unrestricted use, distribution, and reproduction in any medium, provided the original work is properly cited.

The license is subject to the Beilstein Journal of Organic Chemistry terms and conditions:

(http://www.beilstein-journals.org/bjoc)

The definitive version of this article is the electronic one which can be found at: doi:10.3762/bjoc. 9.9 